\title{
Primeiro registro no Brasil de Erythrina velutina Willd. como hospedeira de Tetranychus neocaledonicus (Acari: Tetranychidae)
}

\begin{abstract}
PODEROSO, J.C.M. ${ }^{1 *}$; RIBEIRO, G.T. ${ }^{1}$; NÁVIA, D. ${ }^{2}$; PASSOS, E.M. ${ }^{3}$; GONÇALVES G.B. ${ }^{1}$; CORREIAOLIVEIRA, M.E.'; DANTAS, P.C. ${ }^{1}$

${ }^{1}$ Universidade Federal de Sergipe, Departamento de Engenharia Agronômica, Av. Marechal Rondon, s/n, CEP: 49100-000, São Cristóvão-Brasil *juliopoderoso@yahoo.com.br ${ }^{2}$ EMBRAPA/ Recursos Genéticos e Biotecnologia, Caixa Postal 02372, CEP: 70770-900, Brasília-Brasil ${ }^{3}$ Departamento de Engenharia Agronômica, Fitossanidade, Área Entomologia, Universidade Federal Rural de Pernambuco, Rua Dom Manoel de Medeiros, s/n, Dois Irmãos, CEP: 52171-900, Recife-Brasil
\end{abstract}

\begin{abstract}
RESUMO: Os ácaros tetraniquídeos representam importantes pragas para diversas culturas agrícolas em todo o mundo. Durante a prospecção em mudas de Erytrina velutina no distrito de São Cristovão, Estado de Sergipe, Brasil, a ocorrência destes foi observada em 15\% das mudas que foram levadas ao laboratório para a caracterização dos danos. As mudas apresentavam sintomas de redução e encarquilhamento do limbo. Foram coletados 100 indivíduos destas plantas, os quais foram montados em lâminas de microscopia para a identificação taxonômica. Os ácaros foram identificados como pertencentes à espécie Tetranychus neocaledonicus (Acari: Tetranychidae). Este é o primeiro relato em E. velutina, como hospedeira para T. neocaledonicus no Brasil.
\end{abstract}

Palavras-chave: ácaro vermelho, praga florestal, viveiro

\begin{abstract}
First Brazilian report of Erythrina velutina Willd. as host of Tetranychus neocaledonicus (Acari: Tetranychidae). Spider mites are important pests to several crops worldwide. During prospecting in Erytrina velutina specimens from São Cristovão District, Sergipe State, Brazil, their occurrence was observed in 15\% seedlings, which were taken to the laboratory for description of damages. The seedlings presented leaf blade reduction and crumpling symptoms. One hundred mites were collected from these seedlings and mounted on microscope slides for taxonomic identification. The identified mites belonged to the species Tetranychus neocaledonicus (Acari: Tetranychidae). This is the first report of E. velutina as host for T. neocaledonicus in Brazil.
\end{abstract}

Key words: spider mites, forest pest, nursery

O gênero Erythrina (Família Fabaceae) é largamente conhecido, com ocorrência nas regiões tropicais e sub-tropicais do mundo. Possui cerca de 110 espécies, das quais 70 são nativas da América (Vasconcelos et al., 2003).

As plantas do gênero Erythrina são conhecidas por produzirem alcalóides, flavonóides, isoflavonóides e outras substâncias. Segundo Amer et al., (1991), essas plantas representam a principal fonte de alcalóides tetracíclicos, possuindo atividade semelhante ao curare (um poderoso veneno) que causa paralisia muscular (Decker et al., 1995). Destacam-se entre as plantas medicinais, pelos efeitos no sistema nervoso central e a utilização como traquilizante. Estudos farmacológicos realizados em diferentes laboratórios brasileiros têm demonstrado atividades antinociceptiva, ansiolítica/sedativa, relaxante muscular e antibacteriana de extratos de Erythrina velutina (Marchioro et al., 2005; Dantas et al., 2004; Vasconcelos et al., 2004; Virtuoso et al., 2005; Santos et al., 2007).

O mulungu, Erythrina velutina Willd. (Leguminosae: Papilionoidae), é árvore brasileira de grande porte, comum na caatinga, com potencial para exploração medicinal e florestal. Essa espécie é originária do nordeste brasileiro e floresce na primavera podendo chegar a 12 metros de altura (Lorenzi, 1992; Neill, 1988). E. velutina

Recebido para publicação em 30/10/2008

Aceito para publicação em 15/05/2010

Rev. Bras. PI. Med., Botucatu, v.12, n.3, p.398-401, 2010. 
apresenta bom desenvolvimento no campo, sendo comum a utilização em programas de recuperação de áreas degradadas. A madeira leve pode ser utilizada na confecção de tamancos, jangadas e palitos de fósforo. Além disso, frequentemente é utilizada como mourões de cerca, pela facilidade de plantio por estacas (Lima, 1989).

Na medicina popular E. velutina é conhecida pela ação sudorípara e sedativa (Rabelo, 2001). A infusão das cascas é empregada como calmante e sedativo para tosses e bronquites, bem como para tratamento de verminoses e hemorróidas. E o decocto é utilizado para acelerar a maturação de abscessos gengivais (Lorenzi \& Matos, 2002).

O presente trabalho teve como objetivo inspecionar mensalmente as mudas de mulungu, identificar possíveis pragas e caracterizar os danos causados por estas. As mudas foram produzidas no viveiro de espécies florestais nativas da Universidade Federal de Sergipe, foi feito isolamento das mudas danificadas e o agente dos danos.

As mudas de mulungu foram inspecionadas mensalmente, ao longo de um ano de avaliação, no viveiro de espécies florestais nativas da Universidade Federal de Sergipe, em São Cristovão (105 55' 50" S, $\left.37^{\circ} 06^{\prime} 18^{\prime \prime} \mathrm{W}\right)$, Sergipe. E em janeiro de 2005, verificouse a presença de ácaros em mudas de mulungu.
Foram preparadas lâminas de machos e fêmeas, separadamente, sendo as fêmeas montadas em grupos de cinco, em posição dorso ventral, e os machos isoladamente, em posição lateral.

A identificação foi realizada em microscópio de contraste de fase e as estruturas de maior importância taxonômica fotografadas, com um sistema de captura de imagens, composto por câmara digital acoplada ao microscópio e ao microcomputador. Dentre as estruturas fotografadas pode-se citar o eupatídio do tarso da fêmea e o edeago do macho. Com o eupatídio do tarso, as fêmeas tecem teia e a proporção entre largura e o comprimento dessa estrutura é de grande importância para a identificação de espécies de Tetranychus. De modo semelhante, cada espécie da família apresenta o edeago com forma diferente, por isso essa característica é também de extrema importância taxonômica (Figura1).

No início da infestação as folhas apresentaram pontos cloróticos e, posteriormente, encarquilhamento (Figura 2). Plantas com alta infestação apresentaram desfolha. Aproximadamente $15 \%$ das mudas de mulungu de 415 plantas estavam infestadas. Os ácaros foram identificados como Tetranychus neocaledonicus André, 1933 (Tetranychidae).

Os ácaros de coloração vermelha carmim na região lateral do corpo e alaranjados na região

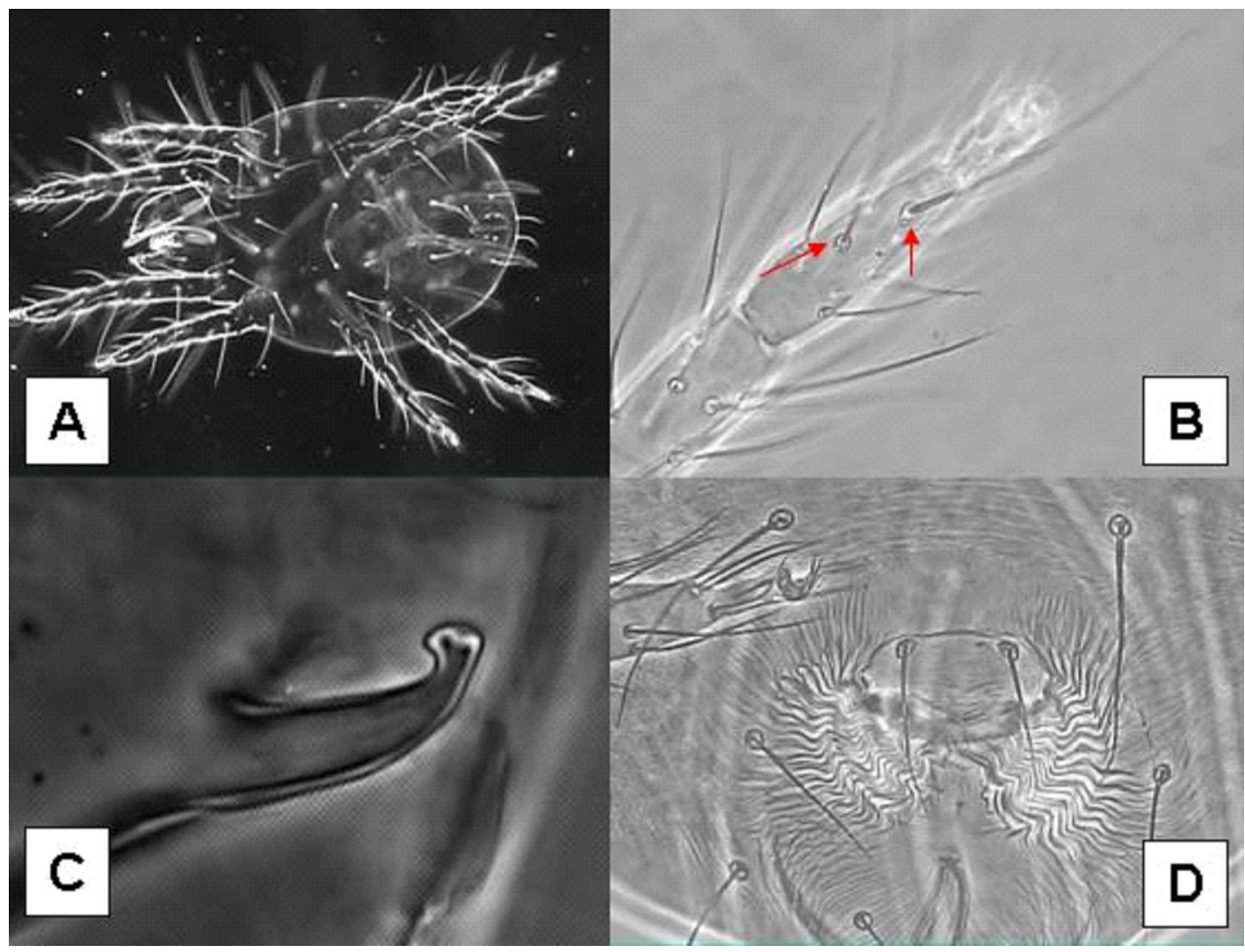

FIGURA 1. Micrografias de Tetranychus neocaledonicus. (A) aspecto geral de fêmea; (B) tarso I de fêmea com um par de setas duplex; (C) detalhe do edeago (macho); (D) região genital da fêmea. 


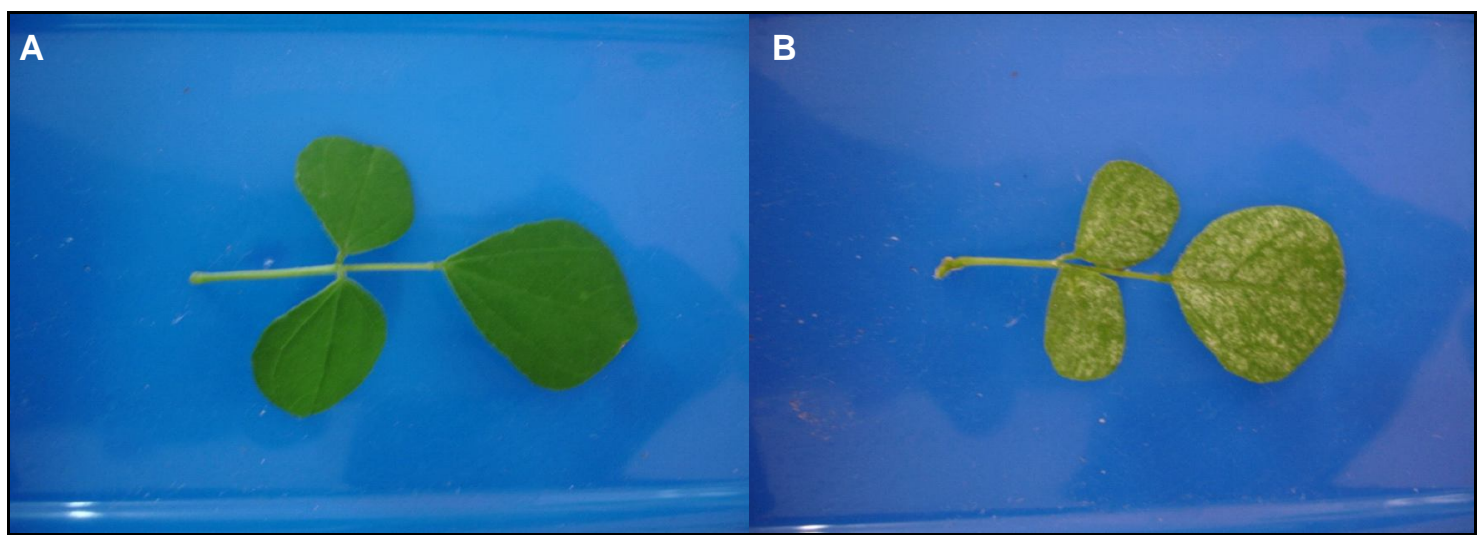

FIGURA 2. Folhas de mulungu: A. sem os ácaros; B. infestadas e com sintoma de encarquilhamento.

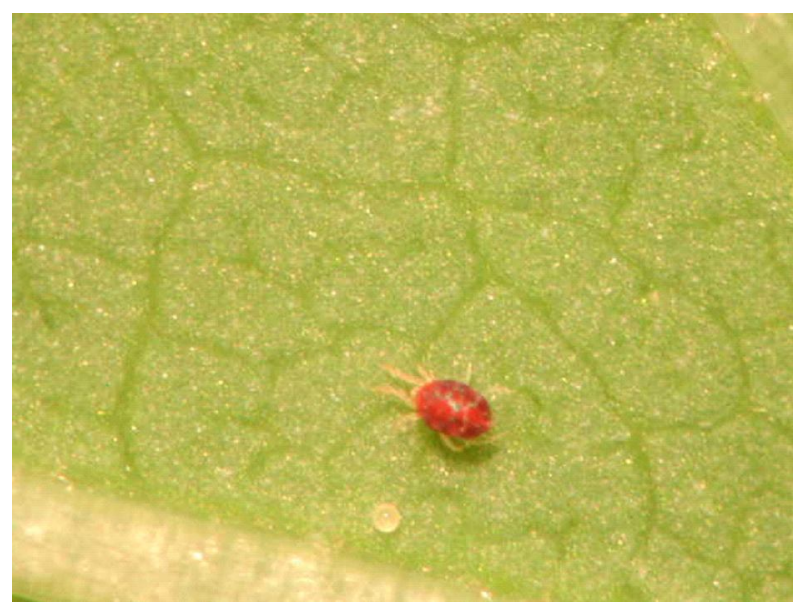

FIGURA 3. Detalhe do ovo e do ácaro do mulungu (Erythrina velutina).

dorso-central, formavam colônias na superfície inferior das folhas, onde produziam grande quantidade de teias e depositaram ovos amarelos globosos (Figura 3).

Os Tetranychidae são uma importante família de ácaros pertecentes a ordem Prostigmata, que engloba algumas espécies que causam perdas significativas tanto em cultivos agrícolas como em plantas ornamentais. Estes organismos possuem desenvolvimento rápido, fácil dispersão e colonização devido a numerosa população (Bonato \& Gutierrez, 1999; Othman \& Zhang, 2003). A espécie $T$. neocaledonicus foi inicialmente descrita em algodoeiros de Nova Caledônia (Oceania) e atualmente é relatada em cerca de 430 hospedeiros, com ampla distribuição geográfica em áreas tropicais e subtropicais do mundo, sendo também considerada uma importante praga em cultivos na Índia (Goff, 1986; Bonato \& Gutierrez, 1999). No Brasil é de comum ocorrência em algodão e mamona, sobretudo no Nordeste. Porém, também tem sido relatada em diversas plantas ornamentais e frutíferas. Este é o primeiro relato de mulungu como hospedeira de T. neocaledonicus; entretanto, três outras espécies do gênero - E. cristagalli L., $E$. cubensis $\mathrm{C}$. Wright e E. fusca Lour - já haviam sido relatadas como hospedeiras desse mesmo ácaro (Flechtmann, 1970). Apesar da ampla gama de hospedeiros conhecidos desta espécie de ácaro dentre as espécies produzidas no viveiro florestal da UFS onde se encontravam Enterolobium contortisiliquum Vell. Morong. (LeguminosaeMimosoideae), Inga uruguensis Hook \& Arn. (Fabaceae), Lonchocarpus sericeus (Poir.) Kunth (Fabaceae) Sapindus saponaria L. (Sapindaceae), Caesalpinia echinata Lam. (Leguminosae), Caesalpinia férrea L. (Leguminosae), Tapirira guianensis Aubl. (Anacardiaceae), Schinus terebinthifolius Raddi. (Anacardiaceae), Cassia grandis L.f. (Leguminosae) apenas em mudas de $E$. velutina foram encontrados ácaros.

Uma hipótese que pode justificar a ocorrência desses ácaros fitófagos em viveiro é a redução de inimigos naturais, principalmente os ácaros predadores, fato que pode ser atribuído à aplicação incorreta de inseticidas, fungicidas cúpricos e acaricidas. Condições climáticas favoráveis aos ácaros fitófagos e adubações de nitrogênio inadequadas para a planta também podem favorecer direta e indiretamente a explosão populacional desses ácaros (Flechtmann, 1983).

Os danos causados por T. neocaledonicus observados nesta pesquisa, evidenciam a necessidade de estudos na área florestal, visando o manejo desse ácaro. Além disso, os conhecimentos sobre a ação seletiva ou tóxica dos agrotóxicos usados no controle de pragas no viveiro de mudas nativas da Universidade Federal de Sergipe devem ser sempre revisados, a fim de optar-se por práticas de manejo que favoreçam a preservação e atuação de artrópodes benéficos, realizando assim um possível controle biológico. Por tratar-se de espécie nativa, com grande aplicação na área medicinal, é importante a rápida detecção de 
novas pragas que possam ameaçar o cultivo.

\section{REFERÊNCIA}

AMER, M.A.; SHAMMA, M.; FREYER, A.J. The tetracyclic Erythrina alkaloids. Journal of Natural Products, v.54, n.2, p.329-63, 1991.

BONATO, O.; GUTIERREZ J. Effect of mating status on the fecundity and longevity of four spider mite species (Acari: Tetranychidae). Experimental and Applied Acarology, v.23, n.8, p.623-32, 1999.

DANTAS, M.C. et al. Central nervous system effects of the crude extract of Erythrina velutina on rodents. Journal of Ethnopharmacology, v.94, n.1, p.129-33, 2004.

DECKER, M.W. et al. Erysodine, a competitive antagonist at neuronal nicotinic acetylcholine receptors. European Journal of Pharmacology, v.280, p.79-89, 1995.

FLECHTMANN, C.H.W.; BAKER, E.W. A preliminary report on the Tetranychidae (Acari) of Brazil. Annals of the Entomological Society of America, v.63, n.1, p.15663, 1970.

FLECHTMANN, C.A.H. Dois ácaros novos para o eucalipto, com uma lista daqueles já assinalados para esta planta. Instituto de Pesquisa e Estudos Florestais, v.23, n.1, p.43-6, 1983.

GOFF, M.L. Spider mites (Acari: Tetranychidae) in the Hawaiian Islands. International Journal of Acarology, v.12, n.1, p.43-9, 1986.

LIMA, D.A. Plantas das caatingas. Rio de Janeiro: Academia Brasileira de Ciências. 1989. 245p.

LORENZI, H. Árvores brasileiras: manual de identificação e cultivo de plantas arbóreas nativas do Brasil. São Paulo: Instituto Plantarum de Estudos da Flora Ltda, 1992. 352p.
LORENZI, H.; MATOS, F.J.A. Plantas medicinais no Brasil: nativas e exóticas cultivadas. São Paulo: Instituto Plantarum de Estudos da Flora Ltda, 2002 .544p. MARCHIORO, M. et al. Anti-nociceptive activity of the aqueous extract of Erythrina velutina leaves. Fitoterapia, v.76, n.7, p.637-42, 2005.

NEILL, A.D. Experimental studies on species relationships in Erythrina (Leguminosae: Papilionoideae). Annals of the Missouri Botanical Garden, v.75, n.3, p.886-969, 1988. OTHMAN, Y.; ZHANG, Z.Q. Tetranychidae (Acari: Prostigmata) of Malay Peninsula: Checklist, key to genera and species and description of three new species. Systematic e Applied Acarology, v.8, n.1, p.149-73, 2003.

RABELO, L.A. et al. Homohesperetin and phaseollidin from Erythrina velutina. Biochemical Systematics and Ecology, v.29, n.5, p.543-4, 2001.

SANTOS, M.R.V. et al. Relaxant effect of the aqueous extract of Erythrina vellutina leaves on rat vas deferens. Revista Brasileira de Farmacognosia, v.17, n.3, p.343-8, 2007.

VASCONCELOS, S.M.M. et al. Antinociceptive activities of the hydroalcoholic extracts from Erythrina velutina and Erythrina mulungu in mice. Biological Pharmaceutical Bulletin, v.26, n.7, p.946-9, 2003.

VASCONCELOS, S.M. et al. Central activity of hydroalcoholic extracts from Erythrina velutina and Erythrina mulungu in mice. Journal of Pharmacy and Pharmacology, v.56, n.3, p.389-95, 2004.

VIRTUOSO, S. et al. Estudo preliminar da atividade antibacteriana das cascas de Erythrina velutina Willd., Fabaceae (Leguminosae). Revista Brasileira de Farmacognosia, v.15, n.2, p.137-42, 2005. 